\title{
Community Support or Funding Amount: Actual Contribution of Reward-Based Crowdfunding to Market Success of Video Game Projects on Kickstarter
}

\author{
Oguzhan Aygoren ${ }^{1, *}$ and Stefan Koch ${ }^{2}$ \\ 1 Department of International Trade, Bogazici University, Bebek, 34342 Istanbul, Turkey \\ 2 Department of Business Informatics-Information Engineering, Johannes Kepler University, \\ 4040 Linz, Austria; stefan.koch@jku.at \\ * Correspondence: oguzhan.aygoren@boun.edu.tr
}

Citation: Aygoren, O.; Koch, S. Community Support or Funding Amount: Actual Contribution of Reward-Based Crowdfunding to Market Success of Video Game Projects on Kickstarter. Sustainability 2021, 13, 9195. https://doi.org/ $10.3390 /$ su13169195

Academic Editors: Francesco Cappa, Angelo Natalicchio, Riccardo Maiolini, Jakob Pohlisch and Erica Mazzola

Received: 27 June 2021

Accepted: 12 August 2021

Published: 16 August 2021

Publisher's Note: MDPI stays neutral with regard to jurisdictional claims in published maps and institutional affiliations.

Copyright: (c) 2021 by the authors. Licensee MDPI, Basel, Switzerland. This article is an open access article distributed under the terms and conditions of the Creative Commons Attribution (CC BY) license (https:// creativecommons.org/licenses/by/ $4.0 /)$.

\begin{abstract}
The research provides empirical evidence differentiating between market success and funding success in reward-based crowdfunding campaigns of video games and hypothesizes that the actual contribution of crowdfunding is more stemming from community support and feedback rather than funding amount. The paper uses publicly available data by combining three different sources. Project data from Kickstarter, a large crowdfunding website, in the video game category are extracted and matched with market success variables of ratings and revenues from two other public sources namely Metacritic and Steamspy. Regression results indicate that once the project is successfully funded, the funding amount does not have a significant effect on market success variables. On the other hand, the number of backers as a community support variable is a significant determinant of market success in terms of higher revenues and ratings for a project. Whether the project was successfully funded or not moderates some of the relationships. Prior literature is predominantly focused on crowdfunding success in terms of financing. Yet, this study empirically demonstrates that funding does not necessarily indicate that projects will be successful in the market and further shows the actual contribution of crowdfunding to the market success of video game projects is the community engagement, not the funding amount. This study contributes to the rapidly emerging crowdfunding literature by extending its boundaries from the crowdfunding platforms themselves to the differentiated effects of crowdfunding on market success, which has not been studied thoroughly. This paper provides a new avenue of research by suggesting not solely focusing on funding outcomes but understanding, defining and explaining the dynamics of the community aspect in crowdfunding platforms with their repercussions on market success. Future work can also highlight potential differences in these effects between product groups, as well as more holistically assess market success and capture interactions within the community on crowdfunding platforms.
\end{abstract}

Keywords: reward-based crowdfunding; Kickstarter; community engagement; market success; video games

\section{Introduction}

Crowdfunding provides democratization of financing by allowing founders to reach non-institutional funding. Thus, individuals all over the world can demonstrate their project ideas and eliminate the existing value chain structures in the industry. In addition to funding, project founders get support from a community that forms around the project vision. Independent video game developers particularly benefit from such value transfer through crowdfunding platforms like Kickstarter by directly communicating with players even during the development phase of the project [1]. This transformation of players from passive consumers into active participants enhances the developer's creativity as well, which might lead to new opportunities and innovative products. So, a popular video game or even a new genre, which might never have been possible through traditional publisher 
channels, might emerge as a result of this creative endeavor of game developers with the prosumer-investors in a crowdfunding campaign [1].

Extant literature on crowdfunding predominantly focuses on its financing aspect and considers funding success as the ultimate goal of a crowdfunding project, which is defined as the project reaching its funding goal [2-9]. However, crowdfunding platforms are much more than a financing tool, creating other types of values such as learning, testing, bonding, relationships and self-esteem for the project founders and target users [10-12]. So, crowdfunding can assist project founders in increasing their post-crowdfunding performance which we refer to as "market success" in this research.

This paper explores the idea that market success is a separate measure from funding success because funding takes place during the crowdfunding campaign period which is shaped by vision and storytelling. On the other hand, market success is related to the actual product in the market pertaining to the post-campaign period in which it is no more a project to be backed but a product to be sold. So, market success can be first and foremost defined as transforming the vision of the founder into a finished product while keeping up with the promises from the project stage. Market success can be and has traditionally been measured through indicators like sales revenue, perceived product quality, ratings and reviews. In this research, we are interested in uncovering the contributions of reward-based crowdfunding to the market success of video game projects beyond crowdfunding success and the funding amount. In an effort to understand which aspects of crowdfunding affect the market success of projects, this paper presents empirical evidence supporting the notion that the community aspect of crowdfunding is a better predictor of market success than funding amount by combining various data sources focusing on the video game category. Although the literature on crowdfunding has grown in recent years, studies combining several data sources and focusing on the post-campaign performance of crowdfunding projects are very rare, and thus not many insights are available in the literature about the final outcomes of those projects during later lifecycle stages and what influences exist on them.

Crowdfunding allows project founders to reach their potential customers even at the inception stage, which can help to develop the product according to the needs and wants of the market through customer discovery and validation. Therefore, this helps to prioritize customer development whereas traditional value chain structures put emphasis on product development. The customer development model is commonly embraced and applied by startups that are in search of a repeatable and scalable business model because startups operate in the world of unknowns and uncertainties [13]. In customer development, the goal is not to make sales first, but it is to get feedback as soon as and as immediately as possible. Therefore, products are co-created with the target users thus leading to a sense of community and belonging. Mollick [14] also argues that the success of crowdfunding platforms at least partly stems from their value as an engagement tool by providing communities of support. Those communities emerge organically in crowdfunding platforms because people who back projects in crowdfunding do not behave like customers but more like believers of the projects. That is why they are called backers in crowdfunding terminology. One common theme in crowdfunding platforms is the creative nature of the projects regardless of the categories, thus there are lots of uncertainties in production, delivery and sales processes and still many people back projects in spite of those uncertainties. In return, those backers earn the right to comment on the project and can directly affect the development process.

For most projects on the Kickstarter platform, there is at times intense communication developing between the founder and the backers. Backers comment on the project and founders might choose to reply and post an update on the project page, learning and adapting aspects of their project according to the feedback. Then some people visit the project page and decide to become backers and the cycle continues. So, as the number of people commenting and backing the project increases, the more the project page turns into a community. Also, the exclusive nature of comments being only available to backers 
contributes to the feeling of community. Through this exposure and interaction in the broader Kickstarter community, some projects are successful at reaching their funding goals and the rest gets unfunded (fails) if the total funding amount falls short of the goal. Moreover, some projects reach way beyond their goal. A video game called Double Fine Adventure is such an example. Founder Tim Schafer was aiming to get USD 400,000; however, after a month of release, to his surprise, 87,000 people backed the project for a total funding amount of USD 3,336,371. It might make sense to assume that the higher the funding amount a video game project gets, the higher the chances it will be a hit in the market because it would mean the project has more resources for production, marketing, human resources, etc. Also, successful products in the market are expected to have higher revenues and ratings-but is it so? Are projects with higher funding amounts more successful than projects with low funding amounts once they reach their funding goal? How big is the impact of feedback, namely community engagement, on the market success of the crowdfunding projects?

In this context, the present study aims to pursue the following two objectives:

- To investigate the relationship between funding success and market success so that the research area on crowdfunding can be broadened beyond the immediate crowdfunding platforms into product launch and new avenues for research can flourish in the field.

- To explore the role of community support and feedback on market success with the aim of increasing the awareness of project founders about performance metrics in crowdfunding platforms other than funding amount.

Relating funding success to market success is uncommon in the crowdfunding literature; yet, one study relating crowds to market success investigates public firms employing crowdsourcing campaigns for new idea generation [15]. The authors demonstrate that even announcing crowdsourcing campaigns has positive effects on the stock market performance of the company when the brand value is high among the crowd. This insight alone suggests that crowdsourcing is associated with listening to customers and market feedback, which creates a positive signaling effect on performance. Nevertheless, previous studies on crowdfunding focus predominantly on the funding success measure, which is defined as the project reaching its goal (target funding amount). Many project founders aim for reaching the highest amount of funding in the platform, in some cases leading to more than 10 times the goal.

In this research, we seek to explain whether the projects are better off if the founders optimize for community support, feedback and interactions instead of the funding amount once the project is funded. So, readers will understand the influence of the community support with respect to the funding amount when it comes to the market success of reward-based crowdfunding projects in the video game category on Kickstarter.

The originality of our research lies first and foremost in the relevance of our research objectives to advancing our knowledge on crowdfunding and its impacts and second in the methodology and the formation of our dataset. To address those goals, we performed an extensive literature review, collected and merged data from three separate data sources (namely Kickstarter, MetaCritic and Steamspy) and built a research model with a multidisciplinary approach by referring to theories and frameworks in relevant research streams. So, this study contributes to the crowdfunding literature by closing the knowledge gap in identifying the role of community support versus funding amount to market success.

The remainder of this research is structured as follows. Section 2 presents the theoretical background behind the research objectives of the study. This is followed by the research model and hypothesis in Section 3. The research methodology and data collection are described in Section 4. The results are reported in Section 5. Section 6 provides the discussion and finally, Section 7 draws the conclusion with implications, limitations and further research. 


\section{Literature Review}

\subsection{New Product Innovation through Community and Co-Creation}

Historically, new product development was presumed to be the job of the manufacturer only [16]. Firms have tried to innovate products and services by using exclusively their own resources like accumulated knowledge and creative personnel. The situation is now completely altered in an age of accessible information, technology and distributed knowledge. People are demanding and expecting more and more because they can reach the necessary information to improve the products and services, they are using every day. Hence, companies do not only develop new products for customers but also produce new products with them. Organizations realized the relevance of customer involvement in new product development some time ago, and they started to look for ways to include them to the process. One way to do this is to include lead users, who face the needs in a marketplace before the majority of people, and then develop a solution to those demands [17-19]. Von Hippel [17] argues that innovative users spend time and effort on new product development because they want that product as much or even more than the manufacturer does. Furthermore, the role of technological uncertainty or novelty of technology is stated as an antecedent to customer involvement in new service development [20].

New product development is not a dictatorship solely owned by the firm anymore, it is a democracy [16]. Democracy requires contributions from many sides. In this case, customers, suppliers, employees all can contribute to new product development, using open innovation strategies [21]. The problem is how to include and attach them to the innovation and development process. Scholars suggested different strategies to successfully integrate customers into innovation processes. Kaulio [22] selected and analyzed seven different methods for involving customers in product design from different fields including marketing, quality management and ergonomics. His analysis results showed that different methods can support the inclusion of the customers in differing phases of product design but especially three phases: specification, development of a concept and prototyping.

On the other hand, von Hippel [23] suggested toolkits to transfer the need-related aspects of products and services to consumers instead of understanding user needs and demands which is becoming harder and harder. Piller and Walcher [24] suggested that manufacturers use toolkits for idea competitions to gather innovative ideas as well as solutions from users. They claimed that idea competitions encourage users to participate in an open innovation process. Lagrosen [25] revealed that a cross-functional team structure is better for new product development in manufacturing firms in his explorative study. He also suggested that in the best case, ideally, customers should be included in the teams but not all customers are suitable for such a relationship.

Sawhney et al. [26] indicated the Internet to be a possible venue for co-creating value with customers. They emphasized the impact of the Internet on processes of collaborative innovation, which is a key aspect of value co-creation, and outlined its characteristics as a platform for customer engagement such as enhanced reach, interactivity, speed, persistence, as well as flexibility and suggested that firms could be able to employ these capabilities of the Internet to engage users in collaborative product and service innovation. Social media platforms are a good example of their suggestions. Firms are using social media platforms to engage customers and involve them in their idea creation processes, including via idea competitions. Supporting these ideas, Füller et al. [27] coined the term "communitybased innovation", which is simply referring to innovation through members of online communities. Online communities can accumulate a vast amount of product know-how. Members of the communities like to share and earn respect from other members. In their study, Füller et al. [27] explained how to identify and reach online user communities as well as to communicate with their members to get useful input for new product or service development. Füller et al. [28] further found that consumer creativity, identification with the brand community, as well as brand-specific emotions and attitudes including passion and trust and finally, brand knowledge constitute important determinants of community members' eagerness to share ideas and knowledge with third parties. 


\subsection{Outcomes and Motivations in Reward-Based Crowdfunding}

Crowdfunding is a growing phenomenon that gained popularity for financing new products and services through platforms like Kickstarter, Indiegogo, Lending Club, Rockethub and many others. The distinction between these platforms is based on the type of contributions backers make. Platforms such as Lending Club are based on equity and lending whereas Kickstarter and Indiegogo are based on rewards and donations. In Lending Club, backers either lend or invest in a new product idea or company. This is a notable form of financing and most research on crowdfunding has studied this fundraising aspect [29-34]. Yet, this study focuses on reward and donation-based crowdfunding where people preorder products or donate money. Kickstarter hosts all types of projects such as films, games, music, art, design and technology. Since 2009, over USD 5.9 billion has been pledged by more than 19 million people, funding more than 204,000 creative projects. In addition, more than 6.7 million people are repeat backers. In order to have a successfully funded project, backers together need to reach the goal (pledge at least the target amount) during the announced period identified by the project founder. Using this definition, Kickstarter indicates that $38.89 \%$ of all projects are successfully funded on the platform whereas a slightly above average share of $43.55 \%$ of projects are successful in the video game category (https:/ / www.kickstarter.com/help/stats, accessed on 27 June 2021).

As a creative business, video games particularly rely on crowdfunding and there is an emerging stream of literature in this field focusing on game production named games crowdfunding [35].

There are several studies investigating the motivation of project founders and backers and also the interaction between them [4]. Backers have motivations such as becoming a part of the vision and helping the founder to turn the vision into reality. They do not see themselves solely as a customer. Altruistic or philanthropic motives also prevail. Consumption, altruism and social belonging are three major motivations of backers [36]. In addition, backers benefit from the exclusive and scarce rewards offered during the crowdfunding campaign [34] (pp. 95-110).

For founders, the findings and conceptual generalizations suggest three broad groups of founder motives, namely, funding success, community engagement and market success as we conceptualize it in this research.

\subsubsection{Funding Success}

This is the fundamental motivation of a crowdfunding campaign. The founder sets a funding goal, and it is necessary to reach the goal in order to get all the committed funding. Otherwise, the project is not funded at all. Mollick [5] indicates many projects succeed with narrow margins or fail with large amounts. Founders engage in many activities to succeed in reaching beyond the funding goals, also because of the signaling effect for further rounds of financing and market success. Mollick and Kuppuswamy [37] indicate that successfully funded projects are more likely to get outside funding due to this signal to other investors.

\subsubsection{Community Engagement and Co-Creation}

Besides raising funds, founders have aims of expanding awareness, forming connections and gaining control whereas backers would like to reap rewards, support others, become a part of a related community, as well as support a cause [38]. Macht and Chapman [11] indicate the benefits of crowdfunding beyond funding as human capital, social capital and psychological capital. Also, Mollick [14] states that the unique value of crowdfunding is the community not the funding. Many founders demonstrate their product ideas through a special video and share as much information as possible with the backers and visitors including pictures, animations, updates, comments, etc. until the target completion date of the project is announced on the website. In that sense, the project page is a virtual community for the product backers and potential backers. Stegmaier [39] indicates that crowdfunding success is highly dependent on building a community, in which participants feel a sense of connection and belonging. 
In an era of increasing uncertainty, startup firms need a customer development mindset instead of a traditional product development model [13]. Customer development suggests that successful startup firms focus on learning and continuously iterate until they discover and validate customers. Von Hippel [16] defines this as a democracy where contributions from many sides are encouraged and intertwined. So, it can be argued that crowdfunding platforms are great places to attract, communicate and collaborate with customers. Firms or individual founders can use crowdfunding to see if users are attracted to their vision when there is no tangible product or service. In addition, backers provide valuable insights to the developers and project founders, which in a sense is helping them to develop the product according to their needs and wants. So, this early market feedback saves firms valuable time and money and guides them during their product development efforts.

\subsubsection{Market Success}

Founders ultimately want to launch a successful product and an organization. Although crowdfunding success is related to reaching the funding goal, market success is how well the project creates and captures value as a finished product. Academic literature traditionally uses market success as a performance variable. Many studies equate it with financial measures of revenues, sales, profits and subjective measures of perceived product quality, ratings, reviews, evaluations, exposure and recall.

\section{Research Model and Hypotheses}

A model was developed based on Day and Wensley's [40] source-position-performance framework by transforming it into a partial mediation model (see Figure 1) in which the crowdfunding project is the source, ratings and reviews act as the positional mediator and video game revenue is the performance outcome measure of market success.

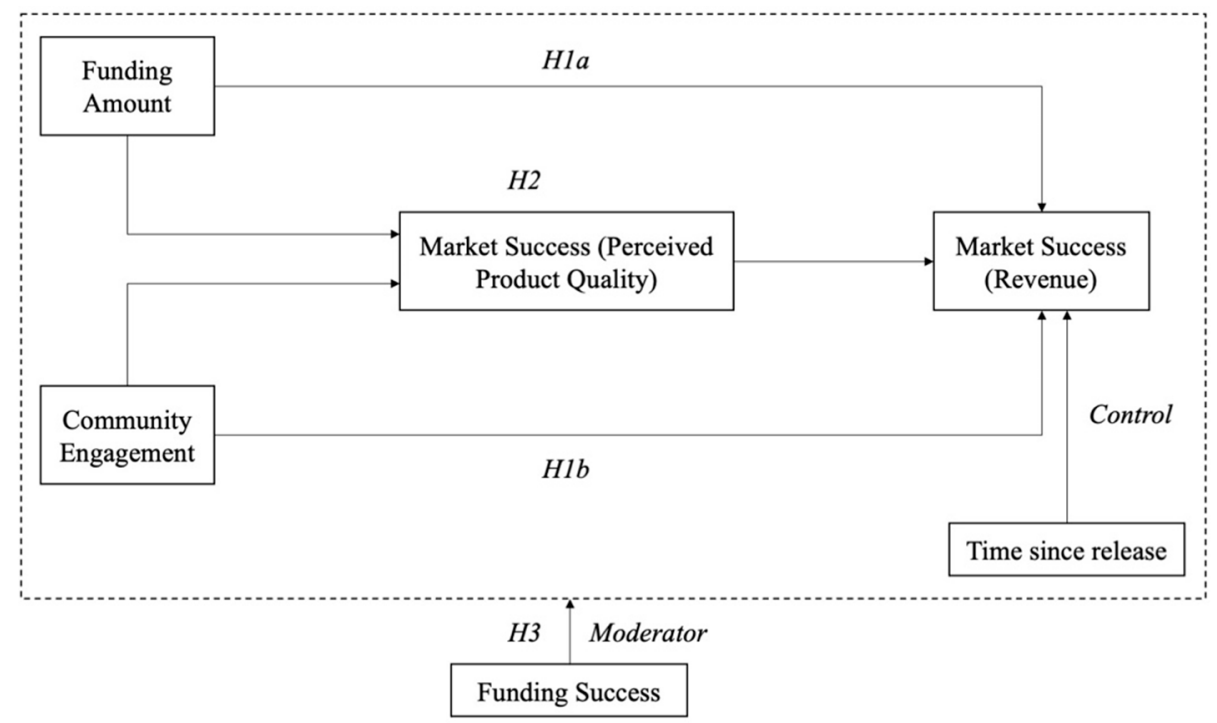

Figure 1. Research model.

The main contributions of crowdfunding to the market success of a project are hypothesized as the financial funding and the customer insight such as co-creation benefits gained during the campaign through community support and engagement. While the first aspect captures the monetary contribution and budget acquired through crowdfunding, which is presumed to increase market success through eliminating resource constraints, the second aspect captures the positive effects of customer feedback and co-design in the form of additional ideas, solutions and modifications of the product vision [20,22]. An additional argument is that these user inputs provide important market and trend information, thus making the final product more attractive and successful [16]. The main theoretical justifica- 
tion can be deduced from the knowledge-based theory of the firm [41-43] extending the resource-based view of the firm [44], which considers knowledge to be the most strategically significant resource of the firm because imitation is difficult and it is socially complex. We argue that the crowdfunding project and the community support and co-creating surrounding it allow the entrepreneur to build superior knowledge resources, particularly connected to market trends and customer insights. Therefore, the following hypothesis is proposed:

Hypothesis 1 (H1). The market success of a realized crowdfunding project as measured by revenue is influenced by the funding amount ( $\mathrm{H} 1 \mathrm{a}$ ) and community engagement ( $\mathrm{H} 1 \mathrm{~b})$, that is, ideas, participation and interaction between the backers and founder during the design (as measured by the number of backers, number of comments and number of updates).

Other than the crowdfunding measures, revenues can be affected by many variables, one of which is product quality. It can be hypothesized that as the perceived product quality increases, revenue increases. In addition, perceived product quality is also a market success metric and presented as the positional mediator in the model. So, crowdfunding measures of funding success and community engagement have an effect on perceived product quality as measured by user ratings, using a similar rationale to the direct effect. In addition, Demiray et al. [45] investigate several crowdfunding platforms in Turkey and demonstrate that community engagement has significant positive effects on community satisfaction and word-of-mouth behavior. So, we propose that another market success metric of perceived product quality mediates the relationship between crowdfunding project outcomes of funding and community engagement through market success as measured by revenue. The way that both aspects influence market success is through the product that results, as more funding and ideas will impact revenue through better quality. Therefore, we formulate the following hypothesis:

Hypothesis $2 \mathbf{( H 2 )}$. The market success metric of rating and reviews as a proxy to product quality partially mediates the relationship of crowdfunding project outcomes of funding amount and community engagement to video game revenues.

We additionally introduce whether the funding was successful or not as a moderator. There are many examples of games that were released on the market although funding on the crowdfunding platform was not successful, for example, "Galactic Game". Although the founders asked to raise money with a goal of USD 45.000, only USD 6.607 were pledged and the project failed to get any funds on Kickstarter. Yet, the game was later released and had a pretty high rating of 88 out of 100 on the Metascore platform, which is predominantly used to evaluate creative projects including video games. These products could still have benefited from the funding with regard to their budgeting and thus success and quality, especially with the funding amount acting as a signal to other potential investors [37] but not directly and thus differently, in case the funding through the platform succeeded. Similarly, while the ideas and community engagement would also have an effect on success, this might also materialize to a different degree, for example, because the project founders took the feedback as less important after the funding failed, or on the other hand, adjusted their plans to a larger extent after failing. In that way, failed funding is actually also perceived as a market signal to the entrepreneur, who will adjust plans and behavior accordingly. We, therefore, propose the following hypothesis:

Hypothesis 3 (H3). The relationship between market success as measured by revenue and funding amount as well as community engagement is moderated by whether the project was successfully funded or not. 


\section{Research Methodology}

\subsection{Background and Research Setting}

For validating the research model, a sample of video games at Kickstarter was used. The video game industry is one of the best-suited contexts to study the phenomenon of crowdfunding. The industry also constitutes an important economic and cultural factor in itself, 2018 U.S. video game content spend has reached over USD 29 billion, with total consumer spending surpassing USD 36 billion, and an astounding number of $60 \%$ of Americans are reported playing video games daily by Entertainment Software Association (2018). The revenue of the worldwide video game market revenue is estimated to be about USD 150 billion by Juniper Research [46]. The computer and video games industry has changed drastically over the last decade [47]. In particular, with the increase in Internet usage all over the world, and improvements in hardware through new console generations and software, the market is also estimated to grow in the next years. Contrary to popular perception, the age of the average user is presently 31 years and gender distribution is about $48 \%$ female, $52 \%$ male. The industry has similarities to movie and similar entertainment industries, which have relatively short product life cycles and an ongoing struggle between creativity and rationalization [48]. The Internet has had a major effect on products and distribution [47], and this industry has welcomed crowdfunding warmly. On Kickstarter, games account for about $10 \%$ of total projects and thus are in the top five categories and lead with regard to total and successfully funded dollars.

Competitive pressure on companies in this industry is high, and firms try to differentiate through superior customer satisfaction, as well as to decrease their new product development costs and risks [49]. Especially the latter arguments have been used to explain a decrease in creativity [48] by focusing on non-innovative formulas or sequels to successful brands. One additional strategy employed is customer-firm interaction, including especially empowering customers to partake in a firm's decisions at some level and creating possibilities for consumer involvement [50]. One implementation of such a strategy is to provide a toolkit for the customers to enable them to create new products [50-52]. BurgerHelmchen and Cohendet [53] distinguish between two types of communities that can interact with firms directly or indirectly. A first community is "communities of specialists", including game designers, scriptwriters, sound designers, graphic artists, sound designers and software programmers employed by the firm to create content. The fast-increasing user community forms the second type, which consists of mostly virtual communities of gamers. This second group is constituted by virtual communities of consumption, for example, brand communities, and can achieve value for firms through different paths. They might support a product and thus act as an independent customer support unit instead of the company, promote the firm's brand and increase loyalty to a particular product or firm, or act as a source of ideas for new products [53].

\subsection{Methodology and Data Collection}

To answer the research question, the main methodological approach was to collect and merge secondary data from a variety of sources for quantitative analysis. The following description lists the different steps and sources, as well as how data selected were respectively merged.

The starting point was video game projects on Kickstarter. The Kickstarter data were extracted with the tools provided by the CrowdBerkeley initiative. The CrowdBerkeley database provides scrapped data from leading crowdfunding platforms with specific schema and variables [54].

The resulting dataset for further analysis includes 6370 video game projects on Kickstarter between 2009 and 2015. Of the projects, 22.4\% were successfully funded, reaching and even exceeding their goals.

In the next step, for each video game project identified at Kickstarter, the Metacritic platform was queried for information. Short product cycles and continuous inflow of new projects make it difficult for users to select which game to play, so they consult, as well as 
exchange ideas and opinions on, product review websites such as Metacritic. This website provides users both expert and also user ratings. Data collection was done automatically using a computer program and an API, with a separate query for each possible platform. For each project matched, the Metacritic rating, the user rating, release date, developer and publisher are retrieved and saved. Metacritic and user ratings are only released in case four different ratings in the respective category are available. In cases of a release on several platforms with ratings, the ratings are averaged. In many cases, a direct match was not possible, as the Kickstarter project titles included additional information. One example is the project "Pillars of Eternity (formerly Project Eternity)", which was later released as "Pillars of Eternity". Accordingly, for all games without a full match, an additional query removing all characters after special characters like "(", "-" or ":" was used. In these cases, an additional check was done for the publisher or developer to match with the project developer or founder. In addition, the release date according to Metacritic was checked against the Kickstarter date, and all projects with a release date before the Kickstarter date were removed as well. A Metascore is assigned by the experts on the website whereas user ratings are actual review scores from the game players.

Finally, in addition to reviews and ratings, revenue data were extracted from Steamspy platform. Steamspy is a website that was launched in 2015 and uses an application programming interface for the Steam software distribution service and its publicly available data from 2018 onwards, to estimate the number of sales and some other measures like playtime. These data were collected and matched in the same manner as described above. Anecdotal evidence in trade literature like Gamasutra [55] or PCGamesN [56] so far suggests the estimates are reasonably close to reality.

The final sample for hypotheses testing therefore consists of projects from Kickstarter in the category of video games that have a full match in Metacritic and Steamspy with user or Metacritic ratings on at least one platform, or a partial match with the matching developer or publisher, with a release date after Kickstarter date. The final dataset for analyzing the success of released video games, as retrieved according to the description above, consisted of 179 games. Figure 2 shows an outline of the data collection process.

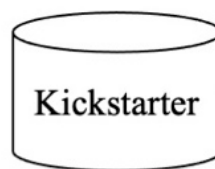

Access via CrowdBerkeley database (retrieval of video game projects with funding amount and success, goal, number of backers, number of updates, number of comments)

Access via API and match based on project title, developer name and release date
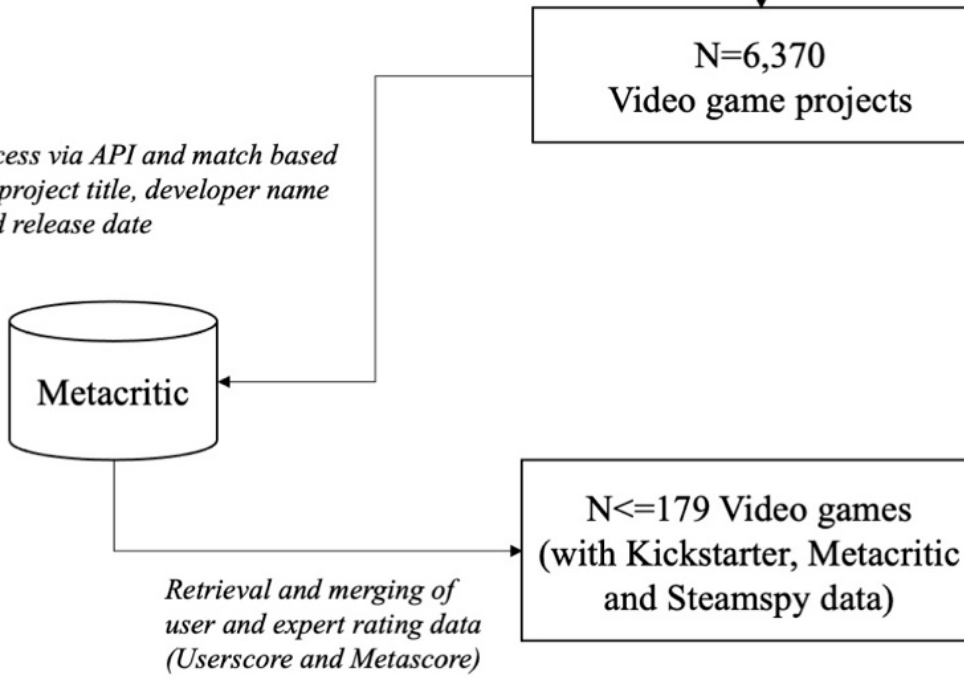

$\mathrm{N}<=179$ Video games (with Kickstarter, Metacritic and Steamspy data)

Figure 2. Data collection process. 


\subsection{Measures}

\subsubsection{Video Game Revenues (from Steamspy)}

Revenue and sales numbers are among the best measures for market success. Revenue numbers are not widely available and have often limited reliability and also might be confidential. Yet, the Steamspy platform discloses estimations of these numbers from the Steam platform. Revenue is used as the final outcome in this research.

\subsubsection{Perceived Product Quality (from Metacritic)}

Ratings are used as an outcome and success measure to capture the perceived product quality. Variability and continuous inflow of new projects make it difficult for users to select which game to play, so they consult and exchange ideas on product review websites such as Metacritic. These websites generally provide users an expert rating and a user rating. Tellis and Johnson [57] and Tellis et al. [58] also provide arguments that ratings constitute a useful source of quality information and have important strategic and financial impacts. In our setting of the video game industry itself, it was widely publicized that publisher Bethesda was due to pay a bonus to developer firm Obsidian contingent on a game achieving a particular average rating. Also, the timing of ratings is relevant as expert ratings are in most cases provided at the release date of a game by professional testers, who are generally in the employment of a media platform. User ratings are submitted by users on a rating platform from the release date onward. Amatriain et al. [59] also focus on the usage and differences of user and expert ratings in the context of the movie industry. We, therefore, employed rating information of both types, in addition to revenue numbers, as outcome measures of market success.

\subsubsection{Community Engagement (from Kickstarter)}

Ongoing communication between project founders and the backers is seen as the source of community engagement. So, the number of backers, number of comments and number of updates as provided by the Kickstarter platform were used as the community engagement metrics. In the regression analysis, the average number of comments and the average number of updates were used. They were calculated by dividing those variables by the number of backers. These measures were widely used in crowdfunding research [2].

\subsubsection{Funding Success (from Kickstarter)}

This variable captures whether the project is successful or not. If the project funding reaches or goes beyond its goal, the variable is 1 , otherwise 0 .

\subsubsection{Funding Goal (from Kickstarter)}

This is an important measure since it indicates the threshold for whether the project is funded or not. If the goal is too high, it could demotivate the backers and if it is too low, the project is easily funded and still, it could demotivate the backers $[4,60]$. Therefore, this number should reflect the actual need of the project instead of an arbitrary number.

\subsubsection{Average Funding Amount (from Kickstarter)}

This measure is computed as the total funding amount divided by the number of backers. This number reflects the commitment of backers.

\subsubsection{Percentage of Goal (from Kickstarter)}

This number shows how much of the goal is achieved, thus highlighting over- or under-performance. It is also an important measure to indicate whether the project had realistic goals.

Table 1 summarizes the sample characteristics for the overall dataset according to all measures. 
Table 1. Overview of sample characteristics for final dataset of released video games $(n=179)^{1}$.

\begin{tabular}{cccccc}
\hline Variable & Min. & Max. & Median & Mean & S.D. \\
\hline Owners (Steamspy, $\mathrm{n}=164)$ & 0 & $5,118,665$ & 59,323 & 215,908 & 502,199 \\
Players (Steamspy, $\mathrm{n}=164)$ & 538 & $4,254,128$ & 30,542 & 164,433 & 415,378 \\
Playtime per Owner (Steamspy, $\mathrm{n}=164)$ & $0: 06$ & $7: 16: 00$ & $4: 11$ & $9: 29$ & $34: 18$ \\
Revenue (\$, Steamspy, $\mathrm{n}=157)$ & 0 & $51,135,463$ & 702,561 & $3,012,768$ & $6,718,231$ \\
MetaScore (0-100) (Steamspy, $\mathrm{n}=104)$ & 0 & 92 & 70.5 & 65.87 & 17.96 \\
UserScore (0-100) (Steamspy, $\mathrm{n}=148)$ & 12 & 98 & 80 & 77.03 & 15.92 \\
MetaScore (0-100) (Metacritic, $\mathrm{n}=130$ ) & 29 & 94 & 70 & 68.8 & 11.21 \\
UserScore (0-10) (Metacritic, $\mathrm{n}=157)$ & 0.6 & 8.95 & 7.1 & 6.84 & 1.49 \\
Number of Backers & 8 & 73,986 & 1105 & 3,08 & 7583.4 \\
Number of Comments & 0 & 63,062 & 196 & 1396 & 5737.8 \\
Number of Updates & 0 & 191 & 29 & 34.27 & 25.38 \\
Funding Success (binary) & 0 & 1 & 1 & 0.82 & 0.38 \\
Goal (\$) & 200 & $1,100,000$ & 20,000 & 72,238 & $159,242.1$ \\
Funding Amount (\$) & 41 & $3,987,000$ & 28,805 & 122,831 & $394,868.9$ \\
Percentage of goal (\%) & 0.18 & 2469 & 131.1 & 205.9 & 284,440 \\
\hline
\end{tabular}

${ }^{1} 147$ are successful, 24 are failed and 8 are canceled.

\section{Analysis and Results}

In order to test the hypotheses, we employed a series of regression models. Due to the large skewness of the data, $\log$ transformation was employed for the dependent variable of revenue. Table 2 reports the Pearson correlation coefficients between the variables used and Table 3 demonstrates all regression results for the research model. All VIF (Variance Inflated Factor) scores are below 2, indicating no problem of multicollinearity. For comments and updates, the average number over the lifetime of the campaign was used to eliminate the influence of different time horizons by dividing the number of comments and number of updates by the number of backers. Similarly, we added the days since the product release as a control variable for the market success measure of revenue in the regression models.

Table 2. Pearson Correlation coefficients.

\begin{tabular}{|c|c|c|c|c|c|c|c|}
\hline & Revenue (ln) & Backers & $\begin{array}{l}\text { Comments } \\
\text { (Average) }\end{array}$ & $\begin{array}{c}\text { Updates } \\
\text { (Average) }\end{array}$ & $\begin{array}{c}\text { Average Funding } \\
\text { Amount }\end{array}$ & $\begin{array}{c}\text { Percentage } \\
\text { of Goal }\end{array}$ & User Score \\
\hline Revenue (ln) & 1 & & & & & & \\
\hline Backers & $0.339 * *$ & 1 & & & & & \\
\hline Comments (average) & 0.132 & $0.235 * *$ & 1 & & & & \\
\hline Updates (average) & $-0.498^{* *}$ & $-0.219 * *$ & -0.08 & 1 & & & \\
\hline Average Funding Amount & -0.047 & 0.095 & $-0.267^{* *}$ & 0.109 & 1 & & \\
\hline Percentage of Goal & $0.247 * *$ & 0.087 & 0.033 & -0.107 & -0.12 & 1 & \\
\hline User Score & $0.387 * *$ & $0.147^{*}$ & -0.023 & $-0.311^{* *}$ & -0.063 & 0.139 & 1 \\
\hline
\end{tabular}

Table 3. Regression model results.

\begin{tabular}{|c|c|c|c|c|c|c|c|c|c|c|}
\hline \multirow{3}{*}{$\begin{array}{c}\text { Dependent Variable } \\
\text { Independent Variables }\end{array}$} & \multirow{2}{*}{\multicolumn{2}{|c|}{$\begin{array}{l}\text { Model } 1 \text { (H1) } \\
\text { Revenue (ln) }\end{array}$}} & \multicolumn{4}{|c|}{ Model 2 (H2) } & \multicolumn{4}{|c|}{ Model 3 (H3) } \\
\hline & & & \multicolumn{2}{|c|}{ User Score } & \multicolumn{2}{|c|}{ Revenue (ln) } & \multicolumn{2}{|c|}{$\begin{array}{c}\text { Revenue } \\
\text { (ln)-Successfully Funded }\end{array}$} & \multicolumn{2}{|c|}{$\begin{array}{l}\text { Revenue (ln)—Not } \\
\text { Successfully Funded }\end{array}$} \\
\hline & B & S.E. & B & S.E. & B & S.E. & B & S.E. & B & S.E. \\
\hline Backers & $5.22 \times 10^{-5 * *}$ & $<0.001$ & $<0.001$ & $<0.001$ & $4.86 \times 10^{-5 * *}$ & $<0.001$ & $5.26 \times 10^{-5 * *}$ & $<0.001$ & 0.001 & $<0.001$ \\
\hline Comments (average) & 0.319 & 0.45 & -2.95 & 3.3 & 0.384 & 0.441 & 0.114 & 0.473 & 2.645 & 1.555 \\
\hline Updates (average) & $-11.438^{* * *}$ & 1.909 & $-49.81 * * *$ & 13.019 & $-9.68 * * *$ & 1.974 & $-12.266^{* * *}$ & 2.266 & -5.741 & 4.751 \\
\hline $\begin{array}{l}\text { Average Funding } \\
\text { Amount }\end{array}$ & 0.001 & 0.007 & -0.006 & 0.045 & 0.001 & 0.007 & -0.001 & 0.008 & -0.003 & 0.014 \\
\hline Percentage of Goal & $0.001 *$ & 0.001 & 0.005 & 0.003 & 0.001 & 0.001 & $0.001 *$ & 0.001 & 0.022 & 0.024 \\
\hline $\begin{array}{l}\text { Time since release } \\
\text { (control) }\end{array}$ & 0.001 & $<0.001$ & & & 0.001 & $<0.001$ & $<0.001$ & 0.001 & $0.002 *$ & 0.001 \\
\hline User Score & \multirow{2}{*}{\multicolumn{2}{|c|}{0.311}} & \multirow{2}{*}{\multicolumn{2}{|c|}{0.093}} & $0.028 * *$ & 0.01 & \multirow{2}{*}{\multicolumn{2}{|c|}{0.316}} & \multirow{2}{*}{\multicolumn{2}{|c|}{0.231}} \\
\hline $\mathrm{R}^{2}$ (adjusted) & & & & & 0.341 & & & & & \\
\hline
\end{tabular}


Model 1 indicates that Hypothesis H1a is partially supported since funding amount does not have an effect on market success, yet, another funding amount measure, the percentage of the goal, has a positive significant effect on the market success measure of revenues. $\mathrm{H} 1 \mathrm{~b}$ is partially confirmed as both the number of backers as well as the average number of updates have an effect on revenues. However, it has to be noted that while the number of backers has a positive impact, the number of updates has a negative impact. In addition, the number of comments does not have any significant effect on market success. The adjusted $R^{2}$ for this model is 0.31 .

According to Model 2, a mediating role of the product quality according to hypothesis $\mathrm{H} 2$ can be confirmed, although it seems to be weak and partial only. Only the number of updates, and again negatively, affect the average user score as a measure of product quality. Funding amount does not have a significant effect on the market success measure of user score, which is used as a proxy for perceived product quality. The mediation model shows a significant positive effect of user score on revenues. In this case, the effects of the number of backers and number of updates are still significant, yet the coefficients are smaller indicating a lower effect when compared to $\mathrm{H} 1 \mathrm{~b}$. The adjusted $\mathrm{R}^{2}$ is 0.341 , a little higher in this model as compared to Model 1.

Model 3 differentiates between successfully funded projects and others. We do indeed find some clear differences, thus confirming hypothesis H3. For successfully funded projects, coefficients for the number of backers and number of updates are stronger when compared to the analysis in H1. In the unsuccessfully funded projects groups, the only significant variable is the time since release, which is the control variable. Adjusted $R^{2}$ is 0.316 for successfully funded projects and 0.216 for unsuccessfully funded projects.

\section{Discussion}

The results indicate that funding success and funding amount do not necessarily and do not in isolation lead to market success. Thus, successful video game projects on Kickstarter might not be successful in user scores and ratings and even in sales. Our analysis testing for the relationship of market success with crowdfunding success shows significant evidence that the reason for such market success according to revenues lies with the community aspect of the crowdfunding platform as hypothesized based on the knowledge-based theory of the firm [41-43].

The single most important positive effect comes from the number of backers in the community engagement metrics. This is a strong signal of the importance of a project with engaged followers, that is, backers who at times altruistically support the project and provide more views, insights and probably show more diversity in backgrounds and opinions. The results overall indicate that project founders should work on increasing the number of people supporting the project instead of increasing the total funding amount. These findings add additional insight into the backer-funding relationship in the literature [2,61]. We believe this is an important finding for crowdfunding where people mostly focus on its financing aspect. Based on the results, an interpretation would be that regardless of how small the contribution amount is, once the project achieves its funding goal, the higher the number of backers, the higher the chance for the project to be successful in the market in terms of revenue and user ratings. This fact can be attributed to the concept of "long tail", indicating the power of selling to more people for lesser amounts [62].

The number of updates was shown to have a negative impact on the user score as an outcome measure, and following through this mediation, the market success measure of video game revenue. Continuous updates might either be distracting from actual development or could, after some threshold, mean that listening to the customer too much dilutes the original artistic vision. Cai et al. [63] also state an inverse U-shaped relationship between crowdfunding success and reward options. Besides, Stegmaier [39] (p. 45) indicates that three updates per week are ideal and beyond that is possibly too much. Ryoba et al. [64] suggest a phased approach to communication where the number of updates needs to be the first priority in the beginning while later stages require polarity 
of comments and readability of updates becoming increasingly important. We, therefore, find overall that comments and updates, although they both are aspects of community engagement and in a sense are two sides of an ongoing conversation, play different roles that warrant additional research.

For projects failing to secure funding on Kickstarter, these aspects have no significant effect, however, the time since release date has a positive effect on revenues. So, it can be argued that failing in crowdfunding does not necessarily act as an indicator or signal for other financing sources. As a limitation of this study, we do not have data regarding the time period between the completion of the crowdfunding project and the market success in terms of projects getting additional funding or experiencing a significant event.

Our analysis indicates that the number of comments does not have a significant effect on the user score ratings and video game revenues. This finding does not indicate that comments are not important. Wang et al. [2] investigates the founder-backer relationship and specifically focuses on the comment numbers, comment sentiment, comment length and compare them with reply ratio, reply length and reply speed. They find that comments and replies have significant positive effects on funding success. On the other hand, for unsuccessful projects on Kickstarter, if problems or weaknesses reported by the community are not addressed or resolved, especially maybe because the project was not successful on the platform, these problems might translate into low ratings. That line of reasoning would also underline crowd intelligence, as the comments seem to have centered on real weaknesses that are afterward criticized by experts and a larger user segment. Capacity resource allocation theory [65] could provide another frame of reference hinting at the cognitive overload of the project founders. It seems that prolonged discussions might distort the image and respectively, the vision of a project, thus maybe discouraging additional backers. If developing a project can be conceptualized as a learning activity on the part of the project founder, too frequent feedback could also overwhelm an individual's cognitive resources according to capacity resource allocation theory [65]. A similar argument can be made using absorptive capacity [66,67], in that the ability of the founder to identify, assimilate, transform and apply valuable external knowledge can be outstripped. Lam et al. [68] have actually found that feedback frequency has an inverted-U relationship with task performance, confirming this notion. Also, Koch [69] has found negative effects of increased use of communication tools on open-source project success, with one explanation put forward that they could lead to a load that is so high that it negatively affects attention and available time dedicated to developers, which could also be spent on development. Martinez-Torres and Olmedilla [70] propose swarm intelligence and social network analysis to uncover innovation solvers to ease the assessment burden on organizations.

As a post-hoc test, we also checked for influences on the funding success and found that community engagement metrics partially mediate the relationship between project attributes and founder experience on funding success on Kickstarter. When the goal and duration increase, possibilities for funding success decrease, in line with prior findings $[4,5]$. However, as the goal increases, it does not decrease the chances of community engagement, on the contrary, it might increase it, possibly due to acting as a signal for a more compelling vision. The presence of a video and an experienced founder are the most important indicators for funding success. Among the community metrics, the number of updates is the most important predictor, followed by the number of backers.

Results thus overall indicate that founder and project characteristics are determinants of the community support and engagement variables of the number of backers, number of updates and number of comments and that these community engagement variables affect two separate success measures, namely, funding success and market success, although in different ways. This means that positioning in the interaction with the community could be necessary in order to focus, to a higher degree, on one of the outcome measures.

Through our results, project founders who are serious about developing a great product for the intended target segment can put more emphasis on determining the goal of the project as realistically as possible in order not to suffer from under-funding and 
over-funding since the former makes your funding effort unsuccessful and the latter might lead to a non-optimal product in the market as reviewed by the experts maybe by boosting self-confidence and causing complacency. Second, founders can focus on attracting more backers instead of attracting more funding. For example, USD 1 donations or rewards at lower values might be some effective strategies for attracting more backers. Third, firms can clearly use crowdfunding platforms as a place for learning from and interacting with customers and should be aware of these possibilities.

\subsection{Implications for Research}

The results of the study present three major contributions to crowdfunding research. First, our study extends the boundaries of crowdfunding research beyond crowdfunding platforms. Relating crowdfunding projects to their market success has not been studied before. Previous research has extensively focused on the crowdfunding success of projects through its financing aspect. Our results indicate that the effect of crowdfunding reaches beyond the crowdfunding platform and impacts the performance of the project.

Second, our work underscores the importance of community engagement and support in crowdfunding. The importance of community engagement has already been the subject of several studies in crowdfunding and also in innovation and new product development literature. However, previous studies did not investigate the role of community engagement beyond the platform where the community exists. Our study explores the relationship of the community with the performance metrics of perceived product quality and revenues as measures of market success.

Third, this study reveals the number of backers as the most significant metric affecting market success. Although previous studies have taken the number of backers, numbers of updates and number of comments as determinants of funding success, they have not tested those community engagement variables against funding amount with respect to their role in product performance. Our results suggest that once the project is successfully funded, the number of backers has the most prominent effect on performance, that is, market success, and funding amount does not provide additional value to market success.

\subsection{Implications for Practice}

Our results provide several practical implications for project founders whose ultimate aim is to have market success. To improve market success, project founders should first aim for funding success; however, they should not aim for a higher funding amount once the project is funded. More successful projects in product review sites and in terms of revenues do not necessarily have higher funding but more backers on the original crowdfunding page. So, when project founders launch the crowdfunding project, they need to optimize for the number of backers. Although not investigated in this study, a highly relevant mechanism for this could be the design of rewards [63]. Other strategies for increasing the number of backers might be to focus on performance measurements in social media to increase user engagement [71].

Our study also suggests that the number of updates might be detrimental to both funding success and market success. The expectations confirmation theory [72,73] can provide an explanation, as the discussion and co-creation signaled through frequent updates during the funding could create expectations in the user community and potentially beyond, which might not be confirmed by the final product, thus leading to dissatisfaction. Also, updates are more important in the earlier phases of product development [64] and have a negative signaling effect in later stages. So, project founders need to be selective in communicating the updates in terms of quantity and frequency.

\subsection{Limitations and Future Research}

This research is subject to several threats to validity and reliability, which can at the same time offer possibilities for future research. First, the study is performed on the single category of video games and results should be treated cautiously when generalizing to all 
categories in crowdfunding. Therefore, further studies can contrast and compare similar analyses of other project categories. Second, a dataset of increased size could improve the reliability of results, although all released video games based on all projects of the largest platform were retrieved at the time of the study. Besides including other platforms, enlarging the dataset would necessitate moving outside of the industry, which creates problems of success measurement and comparability. Increasing the number of ratings would also be a possible way to increase reliability, although we took care to ensure the necessary amount and diversity were used for the analysis. Revenue numbers have not been gathered from the publishers or developers but from a third-party source based on price and owners, and while reported to be close to real numbers, are an imperfect proxy. While the problem of other distribution channels is negligible due to DRM and thus Steam activation, sales and other pricing strategies, if not distributed similarly over all products, could have an impact. We tried to counter this by using the number of owners as a proxy and testing the hypotheses with this independent variable as well, without changes to the results.

It could also be interesting to assess whether any cultural aspects affect game reception. The most significant extension would be to look at refined outcome measures. Although expert and user ratings have some advantages and there are arguments for using them, other and more reliable measures especially covering financial aspects like profits or revenues, or additional aspects and measurements of interest and word-of-mouth, and potentially marketing budgets, would enable a more holistic approach looking at the impact of crowdfunding. Gaining more insight into the backers, especially those providing comments, could also enhance our understanding. With more data on their backgrounds and experiences, the diversity of followers and associated effects could be researched. Analyzing the valence of the comments and performing sentiment analysis can also provide valuable insights on evaluating our discussion of the regression results and potentially the dynamics between comments and updates.

In addition, user privacy concerns on the effects of user behavior can be investigated in future studies in the context of crowdfunding platforms as suggested by Sauro et al. [74]. The privacy issue might be an important and valid discussion point since some crowdfunding platforms explicitly publish the names of backers with the amount they pledge and the exact timing of the pledge. As online backers become more aware and knowledgeable about data privacy, this might come as a salient issue that needs to be identified and researched thoroughly for understanding backer behavior.

Finally, we included only a single, although the most important, crowdfunding platform. In future work, other competing platforms would be useful additions. We find varying degrees of importance in the community engagement metrics. Future studies should uncover the relationship of those variables between themselves. In order to do that, a time series analysis from the Kickstarter platform can be used. Therefore, causal relationships between backers and funding variables can be investigated.

\section{Conclusions}

This research adds to the understanding of crowdfunding as a customer engagement platform or even a foresight platform [75] in addition to its role as a financing platform. We differentiate between funding success and market success and find that the funding amount leads to crowdfunding campaign success but not necessarily market success. Funding success itself has a significant role in market success, and thus still plays an important role that needs further research. Project founders need to engage more people with their projects in order to increase their chances of success. Probably diversity of backgrounds and opinions play a major role in this, underlining basic concepts of innovation and creativity.

In an era of abundant resources, crowdfunding is a viable source for not only financing a project but also building a community. Increasing uncertainty necessitates new venture founders and entrepreneurs to build what customers want through customer discovery and validation. In order to do that, firms need to listen to backers who are potential customers, 
users or players of the project and use the platform for information exchange, discovery and validation.

Within this feedback cycle and engagement, we provide evidence in this research that project founders need to focus on optimizing for the number of backers. However, results need to be evaluated cautiously since we investigate a single category of video games on a single platform.

Through this research, we extend the current discussion in crowdfunding beyond the campaign period and immediate crowdfunding platforms by combining and contrasting its effect on performance which can be accessible and available in other user platforms such as Metacritic and Steamspy. We believe, this methodology provides new avenues for research and generates fruitful discussions in the field.

Author Contributions: Conceptualization, O.A. and S.K.; methodology, O.A. and S.K.; software, S.K.; validation, O.A.; formal analysis, O.A. and S.K.; investigation, O.A.; resources, O.A. and S.K.; data curation, O.A. and S.K.; writing-original draft preparation, O.A. and S.K.; writing-review and editing, O.A. and S.K.; visualization, O.A. and S.K.; supervision, O.A. and S.K. Both authors have read and agreed to the published version of the manuscript.

Funding: This research received no external funding.

Institutional Review Board Statement: Not applicable.

Informed Consent Statement: Not applicable.

Data Availability Statement: Not applicable.

Conflicts of Interest: The authors declare no conflict of interest.

\section{References}

1. Planells, A.J. Video games and the crowdfunding ideology: From the gamer-buyer to the prosumer-investor. J. Consum. Cult. 2017, 17, 620-638. [CrossRef]

2. Wang, N.; Li, Q.; Liang, H.; Ye, T.; Ge, S. Understanding the importance of interaction between creators and backers in crowdfunding success. Electron. Commer. Res. Appl. 2018, 27, 106-117. [CrossRef]

3. Hoegen, A.; Steininger, D.M.; Veit, D. How do investors decide? An interdisciplinary review of decision-making in crowdfunding. Electron. Mark. 2017, 28, 339-365. [CrossRef]

4. Kim, T.; Por, M.H.; Yang, S.B. Winning the crowd in online fundraising platforms: The roles of founder and project features. Electron. Commer. Res. Appl. 2017, 25, 86-94. [CrossRef]

5. Mollick, E. The Dynamics of crowdfunding. J. Bus. Ventur. 2014, 29, 1-16. [CrossRef]

6. Belleflamme, P.; Lambert, T.; Schwienbacher, A. Crowdfunding: Tapping the right crowd. J. Bus. Ventur. 2014, 29, 585-609. [CrossRef]

7. Burtch, G.; Ghose, A.; Wattal, S. An empirical examination of the antecedents and consequences of contribution patterns in crowd-funded markets. Inf. Syst. Res. 2013, 24, 499-519. [CrossRef]

8. Chan, C.S.; Parhankangas, A. Crowdfunding innovative ideas: How incremental and radical innovativeness influence funding outcomes. Entrep. Theory Pract. 2017, 41, 237-263. [CrossRef]

9. McKenny, A.F.; Allison, T.H.; Ketchen, D.J.; Short, J.C.; Ireland, R.D. How should crowdfunding research evolve? A survey of the entrepreneurship theory and practice editorial board. Entrep. Theory Pract. 2017, 41, 291-304. [CrossRef]

10. Efrat, K.; Gilboa, S. Relationship approach to crowdfunding: How creators and supporters interaction enhances projects' success. Electron. Mark. 2019, 12,1-13. [CrossRef]

11. Macht, S.; Chapman, G. Getting more than money through online crowdfunding. Asia Pac. J. Bus. Adm. 2019, 11, 171-186. [CrossRef]

12. Brown, T.E.; Boon, E.; Pill, L.F. Seeking funding in order to sell: Crowdfunding as a marketing tool. Bus. Horiz. 2017, 60, 189-195. [CrossRef]

13. Blank, S. Why the lean start-up changes everything? Harv. Bus. Rev. 2013, 91, 63-72.

14. Mollick, E. The unique value of crowdfunding is not money-It is community. Harv. Bus. Rev. 2016, 4, 2-4.

15. Cappa, F.; Oriani, R.; Pinelli, M.; De Massis, A. When does crowdsourcing benefit firm stock market performance? Res. Policy 2019, 48, 103825. [CrossRef]

16. Von Hippel, E. Democratizing Innovation; MIT Press: Boston, MA, USA, 2005.

17. Von Hippel, E. Lead users: A source of novel product concepts. Manag. Sci. 1986, 32, 791-805. [CrossRef]

18. Franke, N.; Von Hippel, E.; Schreier, M. Finding commercially attractive user innovations: A test of lead-user theory. J. Prod. Innov. Manag. 2006, 23, 301-315. [CrossRef] 
19. Marchi, G.; Giachetti, C.; de Gennaro, P. Extending lead-user theory to online brand communities: The case of the community Ducati. Technovation 2011, 31, 350-361. [CrossRef]

20. Carbonell, P.; Rodríguez-Escudero, A.I.; Pujari, D. Customer involvement in new service development: An examination of antecedents and outcomes. J. Prod. Innov. Manag. 2009, 26, 536-550. [CrossRef]

21. Chesbrough, H.W. Open Innovation: The New Imperative for Creating and Profiting from Technology; Harvard Business Press: Boston, MA, USA, 2003.

22. Kaulio, M.A. Customer, consumer and user involvement in product development: A framework and a review of selected methods. Total Qual. Manag. 1998, 9, 141-149. [CrossRef]

23. Von Hippel, E. Perspective: User toolkits for innovation. J. Prod. Innov. Manag. 2001, 18, 247-257. [CrossRef]

24. Piller, F.T.; Walcher, D. Toolkits for idea competitions: A novel method to integrate users in new product development. R. $D$. Manag. 2006, 36, 307-318. [CrossRef]

25. Lagrosen, S. Customer involvement in new product development: A relationship marketing perspective. Eur. J. Innov. Manag. 2005, 8, 424-436. [CrossRef]

26. Sawhney, M.; Verona, G.; Prandelli, E. Collaborating to create: The internet as a platform for customer engagement in product innovation. J. Interact. Mark. 2005, 19, 4-17. [CrossRef]

27. Füller, J.; Bartl, M.; Ernst, H.; Mühlbacher, H. Community based innovation: How to integrate members of virtual communities into new product development. Electron. Commer. Res. 2006, 6, 57-73. [CrossRef]

28. Füller, J.; Matzler, K.; Hoppe, M. Brand community members as a source of innovation. J. Prod. Innov. Manag. 2008, 25, 608-619. [CrossRef]

29. Cholakova, M.; Clarysse, B. Does the possibility to make equity investments in crowdfunding projects crowd out reward-based investments? Entrep. Theory Pract. 2015, 39, 145-172. [CrossRef]

30. Allison, T.; Davis, B.; Short, J.; Webb, J. Crowdfunding in a prosocial microlending environment: Examining the role of intrinsic versus extrinsic cues. Entrep. Theory Pract. 2015, 39, 53-73. [CrossRef]

31. Macht, S.; Weatherston, J. The benefits of online crowdfunding for fund-seeking business ventures. Strateg. Chang. 2014, 23, 1-14. [CrossRef]

32. Hornuf, L.; Schwienbacher, A. Crowdinvesting-Angel investing for the masses? In Handbook of Research on Business Angels; Edward Elgar Publishing: Cheltenham, UK, 2014; Volume 3, pp. 381-398.

33. Rossi, M. The new ways to raise capital: An exploratory study of crowdfunding. Int. J. Financ. Res. 2014, 5, 8-18. [CrossRef]

34. Best, J.; Neiss, S.; Stralse, S.; Fleming, L. How Big Will the Debt and Equity Crowdfunding Investment Market be? Comparisons, Assumptions, and Estimates. Fung Institute for Engineering Leadership; Fung Technical Report No. 2013.01.15; University of California: Berkeley, CA, USA, 2013.

35. Tyni, H. Game Crowdfunding as a Form of Platformised Cultural Production. PhD Thesis, Tampere University, Tampere, Finland, 2020 .

36. Steigenberger, N. Why supporters contribute to reward-based crowdfunding. Int. J. Entrep. Behav. Res. 2017, 23, 336-353. [CrossRef]

37. Mollick, E.; Kuppuswamy, V. When Firms are Potemkin Villages: Formal Organizations and the Benefits of Crowdfunding. 2014. Available online: https:/ / ssrn.com/abstract=2377020 (accessed on 27 June 2021).

38. Gerber, E.; Hui, J. Crowdfunding: Motivations and deterrents for participation. ACM Trans. Comput. Hum. Interact. 2013, 20, 1-32. [CrossRef]

39. Stegmaier, J. A Crowdfunder's Strategy Guide; Berrett-Koehler Publishers: San Francisco, CA, USA, 2015.

40. Day, G.S.; Wensley, R. Assessing advantage: A framework for diagnosing competitive superiority. J. Mark. 1988, 52, 1-20. [CrossRef]

41. Kogut, B.; Zander, U. Knowledge of the firm, combinative capabilities, and the replication of technology. Organ. Sci. 1992, 3, 383-397. [CrossRef]

42. Spender, J.C. Making knowledge the basis of a dynamic theory of the firm. Strat. Manag. J. 1996, 17, 45-62. [CrossRef]

43. Grant, R.M. Toward a knowledge-based theory of the firm. Strat. Manag. J. 1996, 17, 109-122. [CrossRef]

44. Barney, J.B. The resource-based theory of the firm. Organ. Sci. 1996, 7, 469. [CrossRef]

45. Demiray, M.; Burnaz, S.; Li, D. Effects of institutions on entrepreneur's trust and engagement in crowdfunding. J. Electron. Commer. Res. 2021, 22, 95-109.

46. Report: Gaming Industry Value to Rise 30\%-With Thanks to Microtransactions. Available online: https://www.forbes.com/ sites/mattgardner1/2020/09/19/gaming-industry-value-200-billion-fortnite-microtransactions/ (accessed on 26 June 2021).

47. Marchand, A.; Henning-Thurau, T. Value creation in the video game industry: Industry economics, consumer benefits, and research opportunities. J. Interact. Mark. 2013, 27, 141-157. [CrossRef]

48. Tschang, F.T. Balancing the tensions between rationalization and creativity in the video game industry. Organ. Sci. 2007, 18, 989-1005. [CrossRef]

49. Cadin, L.; Guerin, F. What can we learn from the video game industry? Eur. Manag. J. 2006, 24, 248-255. [CrossRef]

50. Jeppesen, L.B. User toolkits for innovation: Consumers support each other. J. Prod. Innov. Manag. 2005, 22, 347-362. [CrossRef]

51. Parmentier, G.; Gandia, R. Managing sustainable innovation with a user community toolkit: The case of the video game Trackmania. Creat. Innov. Manag. 2013, 22, 195-208. [CrossRef] 
52. Prügl, R.; Schreier, M. Learning from leading-edge customers at The Sims: Opening up the innovation process using toolkits. $R$. D. Manag. 2006, 36, 237-250. [CrossRef]

53. Burger-Helmchen, T.; Cohendet, P. User communities and social software in the video game industry. Long Range Plan. 2011, 44, 317-343. [CrossRef]

54. Yu, S.; Johnson, S.; Lai, C.; Cricelli, A.; Fleming, L. Crowdfunding and regional entrepreneurial investment: An application of the CrowdBerkeley database. Res. Policy 2017, 46, 1723-1737. [CrossRef]

55. Steam Spy and the Specter of Game Sales Transparency. Available online: https://www.gamasutra.com/view/news/280417 /Steam_Spy_and_the_specter_of_game_sales_transparency.php (accessed on 26 June 2021).

56. What Do Developers and Publishers Really Think of Steam Spy? Available online: https://www.pcgamesn.com/steam/steamspy-accuracy-developers (accessed on 26 June 2021).

57. Tellis, G.J.; Johnson, J. The value of quality. Mark. Sci. 2007, 26, 758-773. [CrossRef]

58. Tellis, G.J.; Yin, E.; Niraj, R. Does quality win? Network effects versus quality in high-tech markets. J. Mark. Res. 2009, 46, 135-149. [CrossRef]

59. Amatriain, X.; Lathia, N.; Pujol, J.M.; Kwak, H.; Oliver, N. The wisdom of the few: A collaborative filtering approach based on expert opinions from the web. In Proceedings of the 32nd International ACM SIGIR Conference on Research and Development in Information Retrieval, Boston, MA, USA, 19-23 July 2009; Association for Computing Machinery: New York, NY, USA, 2009; pp. 532-539.

60. Kuppuswamy, V.; Bayus, B.L. Does my contribution to your crowdfunding project matter? J. Bus. Ventur. 2017, 32, 72-89. [CrossRef]

61. Yin, C.; Liu, L.; Mirkovski, K. Does more crowd participation bring more value to crowdfunding projects? The perspective of crowd capital. Internet Res. 2019, 29, 1149-1170. [CrossRef]

62. Anderson, C. The Long Tail: Why the Future of Business is Selling Less of More; Hyperion Press: New York, NY, USA, 2006.

63. Cai, Z.; Zhang, P.; Han, X. The inverted U-shaped relationship between crowdfunding success and reward options and the moderating effect of price differentiation. China Financ. Rev. Int. 2020, 11, 230-258. [CrossRef]

64. Ryoba, M.J.; Qu, S.; Ji, Y.; Qu, D. The right time for crowd communication during campaigns for sustainable success of crowdfunding: Evidence from Kickstarter platform. Sustainability 2020, 12, 7642. [CrossRef]

65. Kanfer, R.; Ackerman, P.L. Motivation and cognitive abilities: An integrative/aptitude-treatment interaction approach to skill acquisition. J. Appl. Psychol. 1989, 74, 657-690. [CrossRef]

66. Cohen, W.M.; Levinthal, D.A. Absorptive capacity: A new perspective on learning and innovation. Adm. Sci. Q. 1990, 35, 128-152. [CrossRef]

67. Zahra, S.A.; George, G. Absorptive capacity: A review, reconceptualization, and extension. Acad. Manag. Rev. 2002, 27, 185-203. [CrossRef]

68. Lam, C.F.; DeRue, D.S.; Karam, E.P.; Hollenbeck, J.R. The impact of feedback frequency on learning and task performance: Challenging the "more is better" assumption. Organ. Behav. Hum. Decis. Process. 2011, 116, 217-228. [CrossRef]

69. Koch, S. Exploring the effects of SourceForge. net coordination and communication tools on the efficiency of open source projects using data envelopment analysis. Empir. Softw. Eng. 2009, 14, 397-417. [CrossRef]

70. Martinez-Torres, R.; Olmedilla, M. Identification of innovation solvers in open innovation communities using swarm intelligence. Technol. Forecast. Soc. Chang. 2016, 109, 15-24. [CrossRef]

71. Saura, J.R.; Palacios-Marqués, D.; Iturricha-Fernández, A. Ethical design in social media: Assessing the main performance measurements of user online behavior modification. J. Bus. Res. 2021, 129, 271-281. [CrossRef]

72. Oliver, R.L. Effect of expectation and disconfirmation on postexposure product evaluations: An alternative interpretation. J. Appl. Psychol. 1977, 62, 480. [CrossRef]

73. Oliver, R.L. A cognitive model of the antecedents and consequences of satisfaction decisions. J. Mark. Res. 1980, 17, 460-469. [CrossRef]

74. Saura, J.R.; Ribeiro-Soriano, D.; Palacios-Marqués, D. From user-generated data to data-driven innovation: A research agenda to understand user privacy in digital markets. Int. J. Inf. Manag. 2021, 19, 102331. [CrossRef]

75. Raford, N. Online foresight platforms: Evidence for their impact on scenario planning \& strategic foresight. Technol. Forecast. Soc. Chang. 2015, 97, 65-76. 